\title{
A PSYCHOMETRIC STUDY \\ OF INCARCERATED \\ PRESIDENTIAL THREATENERS
}

\author{
EDWIN I. MEGARGEE
}

Florida State University

\begin{abstract}
Because of the difficulties associated with studying actual presidential assailants, "proxies" have been used to help us understand those who have a pathological fixation on the presidency. The literature describing two groups of proxies, White House visitors who behave irrationally and people who threaten the president, was reviewed. MMPIs were collected on 45 presidential threateners and 45 nonthreateners evaluated at mental health facilities for federal prisoners. The threateners' characteristics resembled reports of other proxy groups in certain respects, but their criminal histories suggested more antisocial behavior and violence than previously indicated. Their MMPI profiles and classifications on Megargee et al.'s MMPI-based offender classification system were significantly more deviant than those of the nonthreateners. Overall, both samples of mental health patients had more elevated MMPIs and were classified into more pathological types on the MMPI-based typology than offenders previously tested in nonpsychiatric federal correctional settings. Implications were drawn regarding the characteristics of presidential threateners and the validity of the MMPI-based typology.
\end{abstract}

ince 1835,15 homicidal attacks have been launched on
American presidents, presidents-elect, and presidential can-
didates. In the course of these attacks, 10 people, including 4
presidents and 1 presidential candidate, have been killed by the

Author's Note: This research was carried out while I was working for the Intelligence Division of the U.S. Secret Service while on sabbatical from Florida State University. The results of this research were first reported at the eighth annual meeting of the International Differential Treatment Association at Owatonna, MN, on May 11, 1984. I thank Joyce Carbonell for commenting on

CRIMINAL JUSTICE AND BEHAVIOR, Vol. 13 No. 3, September 1986 243-260

(C) 1986 American Association of Correctional Psychologists 
assassins, and 20 others, including two presidential candidates (one of whom was a former president), have been wounded. ${ }^{1}$

Spinoza wrote, "If you want the present to be different from the past, study the past." However, the study of presidential assailants is complicated by the fact that their attempts have taken place over a 150-year span and only 6 of the 16 assailants currently survive. ${ }^{2}$ Moreover, the historical and biographical descriptions of these assailants are often biased and riddled with stereotypes, myths, and inaccuracies (Clarke, 1982).

\section{PROXY SUBJECTS}

To help overcome the limitations of studying actual assailants, some investigators have recommended broadening the scope of inquiry to include "proxy" subjects, people who have not (yet) actually attempted to assassinate the president but who have manifested an apparently pathological fixation on the presidency that has brought them to the attention of the authorities (Institute of Medicine Committee, 1984; Takeuchi, Solomon, \& Menninger, 1981). Not only might these subjects provide us with some insights into what Rothstein $(1964,1966,1971)$ hypothesized was a "presidential assassination syndrome," but, in addition, it is these so-called proxies whom Secret Service agents and mental health authorities must evaluate to determine whether they constitute a serious threat to the safety of the president (Baughman, 1962).

One group of proxies that has been investigated consists of visitors to the White House or other governmental offices who behave peculiarly and insist on seeing the president. Such visitors are first screened by White House security personnel and those who seem disturbed are sent to local hospitals, usually St.

an earlier draft and Richard Filson and Marshall Heymann for supplying advance copies of their papers. Although the research was carried out with the assistance and cooperation of the Secret Service and the Federal Bureau of Prisons, the conclusions and opinions are solely my own, and do not reflect official policies, attitudes or opinions of the Treasury or Justice Departments. 
Elizabeth's, for further evaluation (Keller, Peele, \& Sorrentino, 1965). The modal characteristics of 580 "White House cases" who were hospitalized and evaluated in 1927 and 1937 (Hoffman, 1943), 1959 through 1965 (Keller et al., 1965; Sebastiani \& Foy, 1965), and from 1971 through 1974 (Shore \& Filson, 1985; Shore, Filson, Davis, Olivos, DeLisi, \& Wyatt, 1985) have been reported in the literature. Their characteristics remained remarkably consistent over the last half-century. They were typically psychotic, delusional, undereducated, unskilled, unmarried, isolated, middle-aged white men who traveled to Washington to warn the president of some danger or to seek his personal assistance. The vast majority were diagnosed as suffering from schizophrenia or a paranoid state, and more than half had been hospitalized before. Although the proportion of foreign-born individuals declined from $30 \%$ to $11 \%$, that proportion was consistently twice that found in the general population (Shore et al., 1985). Few of these visitors threatened the president, but, as Sebastiani and Foy (1965) noted, this could be an artifact of Secret Service screening, with the threateners being referred to the criminal justice rather than the mental health system.

Threatening the president is a felony, and there have been several studies of the demographic characteristics of men charged with this offense. Weinstein and Lyerly (1969) obtained data from a variety of sources on 137 men who made threats from 1945 to 1965. Rothstein $(1964,1966,1971)$ contributed synopses of 11 threateners incarcerated at the U. S. Medical Center for Federal Prisoners (USMCFP) at Springfield, Missouri, and Logan, Reuterfors, Bohn, and Clark (1984) recently reported on 126 male threateners evaluated at USMCFP in 1981 and 1982.

In many ways these threateners resembled the White House visitors. They tended to be predominantly white, unmarried, unemployed men in their mid-30s. Whereas half the visitors had not advanced beyond the eighth grade, the threateners typically averaged an eleventh- or twelfth-grade educational level. Their most common diagnosis was schizophrenia, and most had prior hospitalizations. Rothstein $(1964,1966,1971)$, noting the similarities among his 11 cases, inferred a "presidential assassination 
syndrome," but Logan et al. (1984) divided their 126 threateners into eight types, depending on the circumstances under which the threat took place: for example, "the intoxicated threatener," "the institutionalized threatener," and "the publicity-seeking threatener."

Although these descriptions resemble many of the profiles of U.S. presidential assassins published after the Kennedy assassinations and before the attacks on Gerald Ford (see Crotty, 1971, 1972; Greening, 1971; Hassell, 1974; Kirkham, Levy, \& Crotty, 1969; Robinson, 1965; Slomich \& Kantor, 1969; Weiz \& Taylor, 1969), Lawrence Freedman, a consultant to the National Commission on the Causes and Prevention of Violence, criticized the use of White House visitors and presidential threateners as proxies for assassins. "No 'syndrome' of potential presidential assassins can be based on writers of threatening letters," Freedman (1971, p. 150) wrote. "Indeed, so far as we know, the threat may be inversely rather than directly related to the act. . . . No United States presidential assassin has ever written directly to threaten the President, as did Rothstein's subjects, or make verbal threats before government authorities, as had Foy's and Sebastiani's subjects."

However, this statement is historically inaccurate. Before he assassinated James Garfield, Guiteau wrote numerous letters that today would be referred to the Secret Service (Baughman, 1962), and before he attacked Andrew Jackson, Lawrence visited the White House and told Vice President Van Buren he would kill him and Jackson if he was not paid the money he felt he was owed by the government (Demaris, 1971). In the modern era, both John Hinckley and Samuel Byck visited the White House before their attempts to assassinate Ronald Reagan and Richard Nixon, respectively, Hinckley posing for a photograph and Byck picketing in a Santa Claus suit (Clarke, 1982). ${ }^{3}$

One drawback to clinical studies of presidential assailants and proxies is that the behavior that brought the individual to the attention of the authorities naturally influences the diagnostic formulation. If, for example, one feels that a preoccupation with the government is symptomatic of a paranoid condition, then one is predisposed to evaluate all such patients as paranoid. Finney, 
Skeeters, Auvenshine, and Smith (1973) also noted that even mental health professionals might be influenced by their emotional reactions in evaluating assassins such as Sirhan B. Sirhan, and recommended the use of objectively scored tests such as the Minnesota Multiphasic Personality Inventory (MMPI).

\section{THE MMPI}

The MMPI is our most widely used and thoroughly researched objective psychometric instrument. Hundreds of studies have attested to its overall validity and clinical usefulness, and dozens have demonstrated its ability to make significant discriminations in correctional settings (Haven, 1970; Gearing, 1979).

In the early 1970s, my colleagues and I derived an MMPIbased offender classification system by cluster analyzing the MMPIs of three samples of youthful offenders at the mediumsecurity Federal Correctional Institution at Tallahassee, Florida (FCI). In subsequent research on a cohort of 1,214 consecutive admissions to the FCI, we empirically determined the characteristics of the 10 alphabetically named groups. Since its publication (Megargee, 1977; Megargee, Bohn, Meyer, \& Sink, 1979), the MMPI-based system has stimulated considerable research (Zager, 1983) and won a high degree of acceptance (Gearing, 1981). The primary purpose of the present study was to contribute to the literature on presidential threateners by using the MMPI to investigate their characteristics and evaluate the nature and extent of their psychopathology.

This study will also be relevant to the validity of the MMPIbased sytem. Louscher, Hosford, and Moss (1983) hypothesized that inmates at the federal penitentiary at Lompoc, California, should be classified into the more antisocial and deviant MMPI types, such as "Charlie," "Foxtrot," and "How," more frequently than our sample at FCI, Tallahassee, as their penitentiary population was more prone to violence than ours. When their prediction was not confirmed, they criticized the validity of the system. 
Unfortunately, Louscher et al.'s sample was biased by several procedural shortcomings. Whereas we had tested all incoming inmates, retesting those who gave random responses, Louscher et al. excused all those who did not wish to participate and did not retest those who failed to answer properly. As it is likely that the least cooperative inmates were those who opted out, it is not surprising that they did not obtain the overrepresentation they expected in the most antisocial MMPI types. Moreover, they failed to classify their subjects correctly, discarding those profiles that were not uniquely classified by the computer program instead of classifying them clinically as the system requires. As a result, only about $520(48 \%)$ of their 1,074 inmates were tested and classified, in contrast to $95 \%$ of our FCI, Tallahassee, population.

Nevertheless, Louscher et al.'s (1983) basic premise was sound. Samples differing in deviance should differ in their MMPI classifications. If presidential threateners are more disturbed than most prison inmates, this should be reflected in their MMPIbased classifications. A secondary purpose of the present research was to investigate this question.

Only one previous study has attempted to use the MMPI with presidential threateners (Kinney, 1979). Unfortunately, instead of using the standard MMPI, Kinney utilized a short form, the "Mini-Mult Prison Questionnaire" (MMPQ), an unpublished instrument of unknown reliability and validity. ${ }^{4}$ As is often the case with short forms, Kinney's results were inconsistent. In comparing 37 presidential threateners confined at the USMCFP with 35 inmates from the general (nonpsychiatric) population at that institution, he found that 19 of the $61 \mathrm{MMPQ}$ scales discriminated significantly. In a partial cross-validation, in which Kinney contrasted his threateners with 34 Virginia state prisoners, only 2 of these 19 scales attained significance. A comparison of his 2 USMCFP samples on the $16 \mathrm{PF}$ and Eysenck Personality Inventory revealed only a chance number of "significant" differences. 


\section{RATIONALE}

The purpose of the present investigation was to compare samples of presidential threateners and nonthreateners from the mental health populations of the Federal Bureau of Prisons on their standard, full-length MMPI scores and on their typological classifications according to the MMPI-based system of offender classification. Given that both groups of offenders are quite deviant, being confined in mental health units within a correctional system, it was hypothesized that both the threateners and the nonthreateners would have pathological MMPI profiles with an overrepresentation of the more disturbed offender types. Nevertheless, it was further hypothesized that the threateners' clinical scale scores would be more elevated than the nonthreateners', and that they would be more likely than the nonthreateners to fall into the most disturbed types on our MMPI-based offender classification system.

\section{METHOD}

\section{SAMPLE}

The mental health files at USMCFP, Springfield, Missouri, and the Federal Correctional Institution at Butner, North Carolina - the Bureau of Prisons' (BOP's) two primary centers for emotionally disturbed inmates-were searched for subjects who were known to the U.S. Secret Service for having engaged in threatening behavior and who had completed MMPIs in their files. A total of 45 cases were identified, 41 from Springfield and 4 from Butner. For each case, the next nonthreatening adjacent case in the mental health file drawer that also had a completed MMPI in its folder was accessed; these latter subjects constituted the control sample of nonthreatening mental health prisoners. ${ }^{5}$

According to Secret Service file data, 641 of the 45 men in the threatener sample $(91 \%)$ were white, $3(7 \%)$ were black, and 1 
(2\%) was Hispanic. Their mean age when they first came to the attention of the Secret Service was 32, with a range from 19 to 55. Their educational level ranged from sixth grade to a master's degree, with a mean grade level of $11 ; 93 \%$ had completed the eighth grade, $47 \%$ had completed high school, and $22 \%$ had completed four years of college.

Only 5 subjects (12\%) were married; $21(49 \%)$ were single, and $16(37 \%)$ were divorced, $7(16 \%)$ more than once, suggesting that the threateners' marital stability and heterosexual maturity were less than optimal. This impression is strengthened by two facts: (1) One thrice-divorced man had murdered one of his wives, presumably the last; and (2) $17(38 \%)$ of the subjects were described as being homosexuals, bisexuals, or transvestites.

The number of threats known to the USSS ranged from 1 to 38, with a mean of 7.4 . Over half $(51 \%)$ of the sample had maintained a continuing interest in the presidency, regardless of the particular person in office, and $73 \%$ had exhibited interest in or threatened other prominent individuals as well.

Thirty-eight of the 45 subjects $(84 \%)$ had previously been confined in both mental health and penal institutions, and an additional $6(13 \%)$ in penal but not mental health settings. Only one had no prior history of confinement. The most common psychiatric diagnosis was schizophrenia; in addition $22(49 \%)$ had been described as suicidal, and it was noted that several had made suicide attempts, one successfully. Twenty-four subjects $(53 \%)$ were reported to have problems relating to alcohol, and $22(49 \%)$ were reported to use drugs or inhalants. Moreover, $39(87 \%)$ had criminal histories apart from their threatening activities, and 31 $(69 \%)$ had been arrested or convicted of crimes of violence, such as assault, armed robbery, arson, rape, and, in 4 cases, murder.

\section{PROCEDURE}

After all the MMPIs had been screened for validity, the two groups' mean scores on the standard clinical scales were compared using t-tests, with the invalid profiles excluded. ${ }^{7}$ Although directional predictions had been made, two-tailed tests were used, 
as no previous MMPI data have been reported on this clinical group.

The 90 profiles were then clinically classified into 1 of the 10 MMPI-based offender types (Megargee et al., 1979); those that were invalid or failed to meet the rules for any type were placed in the unclassified ("Uncle") category. To test the hypothesis that the offenders in the present sample would fall into the more disturbed MMPI types, the two samples were combined and compared with Megargee et al.'s (1979) original normative FCI, Tallahassee, sample. Next, the distributions of offenders in the threatener and nonthreatener samples were compared using chi-square.

\section{RESULTS}

\section{MMPI CLINICAL SCALES}

Eight MMPI profiles were classified as invalid or random, 6 in the threatener sample and 2 in the contrast group. Table 1 presents the means, standard deviations, and tests of significance between the means for all the valid MMPIs. The mean T-scores of the threateners equaled or exceeded a T-score of 70 on 4 scales, 2 (D), $4(\mathrm{Pd}+.4 \mathrm{~K}), 6(\mathrm{~Pa})$, and $7(\mathrm{Pt}+1 \mathrm{~K})$, and exceeded 80 on 1 scale, $8(\mathrm{Sc}+1 \mathrm{~K})$. The mean MMPI scores of the nonthreateners exceeded 70 on 2 scales, 4 and $8 .^{8}$ The t-tests showed that the threateners were significantly higher than the nonthreateners on MMPI scales 4,8 , and $9(\mathrm{Ma}+.2 \mathrm{~K})$. There was also a noteworthy trend $(p=.08)$ for the threateners to be higher on Scale 7.

\section{MMPI TYPOLOGY}

The overall breakdown of the 90 profiles into each of the 10 MMPI types plus the number in "type Uncle" (unclassifiable) for the threateners, nonthreateners, and combined samples is presented in Table 2. 
TABLE 1

Comparison of Patients Who Have Threatened the President with Patients Who Have Not

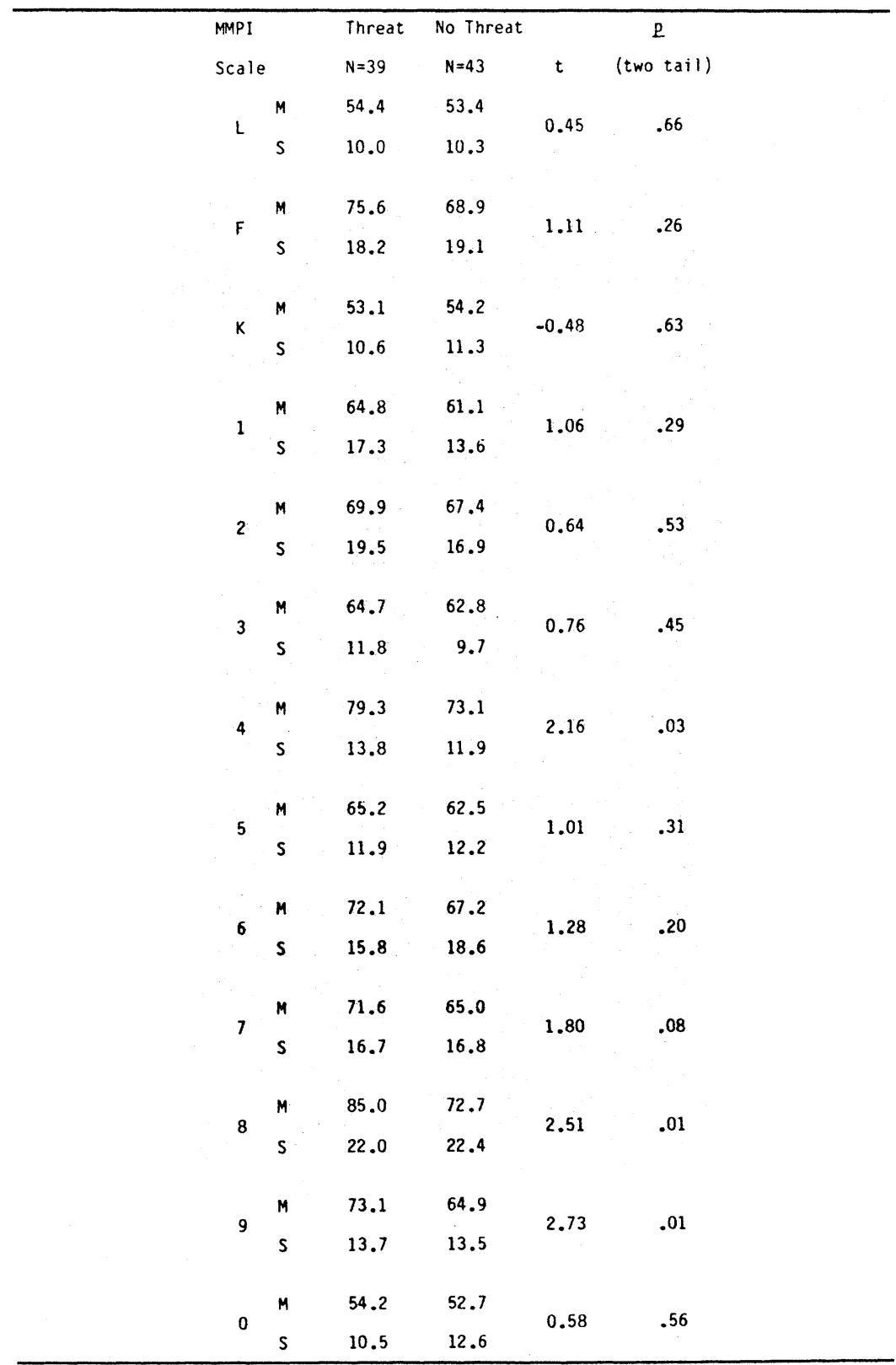


TABLE 2

MMPI Types of Threatening and Nonthreatening Patients

\begin{tabular}{|c|c|c|c|c|}
\hline Pathology & MMPI & & & \\
\hline Level & Types & Threat & No Threat & Total \\
\hline & Item & 4 & 8 & 12 \\
\hline & (I) & $(8.8 \%)$ & (17.8\%) & $(13.3 \%)$ \\
\hline & Easy & 2 & 6 & 8 \\
\hline & (E) & $(4.4 \%)$ & $(13.3 \%)$ & $(8.9 \%)$ \\
\hline Low & Baker & 1 & 1 & 2 \\
\hline & (B) & $(2.2 \%)$ & $(2.2 \%)$ & $(2.2 \%)$ \\
\hline & ADle & 0 & 4 & 4 \\
\hline & (A) & (0\%) & $(8.8 \%)$ & $(4.4 \%)$ \\
\hline & Low & 7 & 19 & 26 \\
\hline & Subtotals & $(15.6 \%)$ & $(42.2 \%)$ & $(28.9 \%)$ \\
\hline & George & 1 & 1 & 2 \\
\hline & (G) & $(2.2 \%)$ & $(2.2 \%)$ & $(2.2 \%)$ \\
\hline & Delta & 4 & 2 & 6 \\
\hline medrum & (D) & $(8.8 \%)$ & $(4.4 \%)$ & $(6.7 \%)$ \\
\hline & Jupiter & 3 & 1 & 4 \\
\hline & (J) & $(6.7 \%)$ & $(2.2 \%)$ & $(4.4 \%)$ \\
\hline & Medium & 8 & 4 & 12 \\
\hline & Subtotals & $(17.8 \%)$ & $(8.9 \%)$ & $(13.36)$ \\
\hline & Foxtrot & 4 & 2 & 6 \\
\hline & (F) & $(8.8 \%)$ & $(2.2 x)$ & $(6.7 \%)$ \\
\hline & Charlie & 6 & 7 & 13 \\
\hline & (C) & $(13.3 \%)$ & $(15.6 \%)$ & $(14.4 \%)$ \\
\hline mign & How & 13 & 10 & 23 \\
\hline & (H) & $(28.9 \%)$ & $(22.2 x)$ & $(25.6 \%)$ \\
\hline & Uncle & 7 & 3 & 10 \\
\hline & $(U)$ & $(15.6 \%)$ & $(6.7 \%)$ & $(11.1 \%)$ \\
\hline & $\mathrm{High}$ & 30 & 22 & 52 \\
\hline & Subtotals & $(66.7 x)$ & $(48.9 \%)$ & $(57.8 \%)$ \\
\hline Totals & & 45 & 45 & 90 \\
\hline
\end{tabular}


Because all the subjects in the present study were among the most deviant in the federal system, it had been hypothesized that both the threateners and nonthreateners would be overrepresented in the more deviant MMPI types. With 11 types and only 90 subjects, it was necessary to reduce the number of cells to conduct statistical tests. As we have done in our previous research, the 4 MMPI groups that have empirically been found to be the least deviant (Item, Easy, Baker, and Able) were grouped together into a "low-pathology" group. The three that have consistently been found in the midrange for deviance (George, Delta, and Jupiter) were combined into a "medium-pathology" group; and the four that have consistently been evaluated as the most pathological (Foxtrot, Charlie, How, and Uncle) were placed together in the "high-pathology" group.

The data showed 26 subjects in the combined patients' samples $(28.9 \%)$ were classified in the 4 low-pathology types, 12 patients $(13.3 \%)$ in the 3 medium types, and $52(57.8 \%)$ in the 4 high pathology types (see subtotals in Table 2). In the original normative samples, 564 offenders $(46.5 \%)$ had been classified into the low types, $242(18.6 \%)$ in the medium, and $408(31.3 \%)$ in the high. Thus, the overall patient sample had only half as many subjects in the least deviant groups and almost twice as many in the most deviant groups. This difference proved to be highly significant (chi-square $=21.34, \mathrm{df}=2, \mathrm{p}<.001$ ).

It has also been hypothesized that, despite the overall deviance of the patients, the presidential threateners would be more likely to fall into the more pathological types than the nonthreateners. This proved to be the case. Among the threateners, only 7 subjects $(15.6 \%)$ were in the 4 low-pathology types and $8(17.8 \%)$ were in the medium, whereas $30(66.7 \%)$ were in the 4 high groups. In contrast, 19 of the nonthreateners $(42.2 \%)$ fell into the low range, 4 in the medium $(8.9 \%)$, and $22(48.9 \%)$ in the high. This difference, too, proved statistically significant (chi-square $=8.10$, $\mathrm{df}=2, \mathrm{p}<.02)$. 


\section{DISCUSSION}

The present investigation differs from previous studies of proxy cases in several important respects. First, whereas previous studies were based on hospital records and interviews, the present research, using Secret Service reports, was able to provide a more complete picture of the nature and extent of the subjects' threatening behavior and prior criminal history. Second, the study used the complete standard-form MMPI scored on all the regular clinical scales and classified according to the MMPIbased offender typology. Third, it made use of a contrast group of nonthreatening offenders who had also been evaluated in a correctional mental health setting.

The demographic description of the 45 male threateners was consistent with previous studies of proxies; they were predominantly white, unmarried individuals with long histories of instability manifested by previous hospitalizations and incarcerations. As in previous studies, diagnoses of schizophrenia and histories of suicidal behavior were common. The present sample was somewhat better educated than those previously reported, however.

Sebastiani and Foy (1965) hypothesized that people who had made overt threats against the president would be more dangerous than the relatively benign White House visitors they had examined. The widespread threatening activities in which many of the present subjects had engaged, the extensiveness of their prior criminal histories, and the number of violent offenses they had committed support Sebastiani and Foy's (1965) speculation. Indeed, 39 of the 45 threateners $(87 \%)$ had at some time been among those regarded as dangerous by the Secret Service.

Of course, all of these factors are interrelated. Once their threats had come to the attention of the authorities, the threateners' psychiatric and criminal histories no doubt influenced the decision to send them to the Bureau of Prisons' mental health facilities at Springfield and Butner. The value of the MMPI data is that they provide an independent quantitative estimate of the threateners' personality functioning and pathology level that is not contaminated by knowledge of their threatening activities 
and previous history or influenced by the fact that they may fit the stereotype of the U.S. presidential assailant. With mean T-scores over 70 on MMPI scales F, 4, 8, and 9, the threatener sample manifested considerable potential for antisocial acting out and violence, and the elevations of 70 or more on scales 2 and 7 , reflecting depression and anxiety, are consistent with the reports of suicidal behavior and the obsessiveness that apparently characterized the threatening activities of some subjects.

Of course, we would expect federal prisoners referred for psychiatric evaluation or treatment to have pathological MMPIs, and, indeed, the mean profile of the nonthreateners was also elevated. However, the threateners' mean scores on MMPI scales 4,8 , and 9 significantly exceeded those of the nonthreatening patients.

It should be emphasized that threateners convicted of federal crimes, sentenced to prison, and referred to the BOP's mental health facilities are a very select group. Not everyone who makes a threat comes to the attention of the authorities; threats uttered in the privacy of one's living room while watching a presidential press conference remain secret, as do all the letters that are written but never mailed.

In 1983, approximately 4,000 people came to the attention of the Secret Service; after investigation, about $3 \%$ were classified as dangerous (Institute of Medicine, 1984, pp. 10-11). It is this minority that is most likely to end up in a prison or hospital, or, as with this sample, in a hospital within a prison.

Mean MMPI profiles can, of course, be deceptive, combining a number of disparate individuals into a mythical composite. For this reason, I place greater reliance on the MMPI-based typology that showed the threateners' profiles were significantly more likely than the nonthreateners' to fall into the most pathological types. (It is important to remember in this regard that the evaluation of each type's pathology and deviance is based on a number of independent empirical investigations and not on the MMPI profile itself.)

Although my primary interest was in the psychometric evaluation of people who have threatened the president, these data are also relevant to the validity of the MMPI-based offender 
classification system. As noted above, Louscher et al. (1983) recently attacked the validity of the system because they did not find an overrepresentation of penitentiary inmates in the most deviant (high range) groups. It appeared that their failure was attributable to biased sampling. However, in view of the extensive histories of deviance among the 45 threateners, if we, too, had failed to find any differences, it would have cast serious doubt on the validity of the MMPI-based typology. The fact that highly significant differences were obtained instead supports its validity.

The antisocial behavior and violence found in the present sample of threateners, as well as the psychopathology revealed in their MMPI profiles and classifications, suggest that threateners might make better proxies than many authorities, such as Freedman (1971), had believed. Future research, systematically investigating the similarities and differences between threateners and actual assailants, would help to evaluate the usefulness of this approach.

Although as a group the threateners were significantly more deviant than the comparison samples, it should be noted that they were classified into 10 of the 11 MMPI types. To the extent that threateners resemble assailants, this argues against the existence of a unitary presidential assassination syndrome, such as Rothstein (1964, 1966, 1971) inferred from his clinical studies of 11 USMCFP threateners, and instead suggests that the typological approaches being pursued by investigators such as Clark (1982), Heyman (1984), and Logan et al. (1984) may prove more fruitful.

It is probably best if future studies of proxies focus primarily on the one characteristic they all share with assailants: namely, a fixation on the presidency. How does this fixation develop? Does it grow out of political beliefs, or is it more related to the symbolic aspects of the president as a father symbol, as psychoanalytic writers such as Socarides (1979) have suggested? What cognitive beliefs or emotional attitudes toward the presidency do these people have in common? Research into questions such as these may provide important clues for the identification, diagnosis, and treatment of people who pose a danger to the president and other prominent political figures. 


\section{NOTES}

1. In this article, "president" will refer to a president of the United States, a presidentelect, or an active candidate for the presidency. "Assailant" will refer to anyone who has actually launched an attack on a president, whether or not the attack was successful.

2. The 16 assailants and their intended victims are Richard Lawrence (Andrew Jackson, 1835), John Wilkes Booth (Abraham Lincoln, 1865), Charles J. Guiteau (James Garfield, 1881), Leon Czolgosz (William McKinley, 1901), John Schrank (Theodore Roosevelt, 1912), Guiseppe Zangara (Franklin D. Roosevelt, 1933), Oscar Collazo and Griselio Torresola (Harry S Truman, 1952), Richard Pavlick (John F. Kennedy, 1960), Lee Harvey Oswald (John F. Kennedy, 1963), Sirhan B. Sirhan (Robert F. Kennedy, 1968), Arthur H. Bremer (George Wallace, 1972), Samuel Byck (Richard M. Nixon, 1974), Lynette Fromme and Sara Jane Moore (Gerald R. Ford, 1975), and John W. Hinckley (Ronald Reagan, 1981).

3. It is likely that a systematic study of the 16 assailants would reveal others who have similarly indicated their fixation on the presidency. I am currently undertaking such a study.

4. In fairness to Kinney's decision to use the MMPQ in his dissertation research, it should be pointed out that one of its authors was Kinney's major professor and department chair.

5. I am grateful to ASAIC (ret.) Robert Kyanko and former senior research psychologist Dr. Leon Wetrogan of the U.S. Secret Service, who identified the sample of threateners and supplied data on their characteristics, and to Drs. Martin Bohn, Jr., and Craig Love of the U.S. Bureau of Prisons, who searched the files at Springfield and Butner and provided the MMPI data.

6. As the 45 men in the nonthreatening contrast group were not known to the Secret Service, comparable demographic data are not available on them.

7. The procedures for determining profile validity are described in detail in Megargee et al. (1979, pp. 111-115).

8. In contrast, the overall mean male MMPI profile for the entire Bureau of Prisons, based on 20,840 subjects tested from October 1, 1981, through June 11, 1985, has no clinical scales with mean T-scores as high as 70 (E. W. Terrie, personal communication, June 11, 1985).

\section{REFERENCES}

Baughman, U. E. (1962). Secret Service chief. New York: Harper \& Row.

Clarke, J. W. (1982) American assassins: The darker side of politics. Princeton, NJ: Princeton University Press.

Crotty, W. J. (1971). Assassinations and their interpretation within the American context. In W. J. Crotty (Ed.), Assassinations and the political order (pp.3-53). New York: Harper \& Row.

Crotty, W. J. (1972, May). Presidential assassinations. Society, 9, 18-29.

Demaris, O. (1971). America the violent. Baltimore: Penguin Books. 
Finney, J. C., Skeeters, D. E., Auvenshine, C. D., \& Smith, D. F. (1973). Phases of psychopathology after assassination. American Journal of Psychiatry, 130, 1379-1380.

Freedman, L. Z. (1971). Psychopathology of assassination. In W. J. Crotty (Ed.), Assassination and the political order (pp. 143-160). New York: Harper \& Row.

Gearing, M. L. II. (1979). The MMPI as a primary differentiator and predictor of behavior in prison: A methodological critique and review of the recent literature. Psychological Bulletin, 89, 929-963.

Gearing, M. L., II. (1981). The new MMPI typology for prisoners: The beginning of a new era in correctional research and (hopefully) practice [Review of Classifying criminal offenders: A new system based on the MMPI]. Journal of Personality Assessment, 45, 102-107.

Greening, T. C. (1971). The psychological study of assassins. In. W. J. Crotty (Ed.), Assassination and the political order (pp. 222-226). New York: Harper \& Row.

Hassel, C. V. (1974, December). The political assassin. Journal of Police Science and Administration, 4, 399-403.

Haven, H. (1970). The MMPI with incarcerated adult and delinquent offenders. F.C.I. Technical and Treatment Notes (Vol. 1, No.1). Tallahassee, FL: Federal Correctional Institution, 32301.

Heyman, M.N.(1984). A study of presidential assassins. Behavioral Sciences and the Law, 2, 131-149.

Hoffman, J. L. (1943). Psychotic visitors to government offices in the national capitol. American Journal of Psychiatry, 99, 571-575.

Institute of Medicine, Committee on Research and Training Issues Related to the Mission of the Secret Service. (1984). Research and training for the Secret Service: Behavioral science and mental perspectives. Washington, DC: National Academy Press.

Keller, G. F., Peele, R., \& Sorrentino, E. A. (1965). The White House cases. Proceedings of the 18th annual medical society of St. Elizabeth's Hospital, April, 122-127.

Kirkham, J. F., Levy, S. G., \& Crotty, W. J. (1969). Assassination and political violence: A report to the National Commission on the Causes and Prevention of Violence. Washington, DC: Government Printing Office.

Kinney, D. R. (1979). Assassin syndrome: Threateners compared to other psychiatric/general inmate groups (Dectoral dissertation, North Texas State University, 1978). Dissertation Abstracts International, 39, 3521.

Logan, W. S., Reuterfors, D. L., Bohn, M. J., Jr., \& Clark, C. L. (1984). A description and classification of presidential threateners. Behavioral Sciences and the Law, 2, 151-167.

Louscher, P. K., Hosford, R. E., \& Moss, C. S. (1983). Predicting dangerous behavior in a penitentiary using the Megargee typology. Criminal Justice and Behavior, 10, 269-284.

Megargee, E. I.(Ed.). (1977). A new classification system for criminal offenders. Criminal Justice and Behavior, 4(2).

Megargee, E. I., Bohn, M. J., Jr., Meyer, J., Jr., \& Sink, M. F. (1979). Classifying criminal offenders: A new system based on the MMPI. Beverly Hills, CA: Sage.

Robinson, G. W. (1965, May). A study of political assassinations. American Journal of Psychiatry, 121, 1060-1064.

Rothstein, D. A. (1964). Presidential assassination syndrome. Archives of General Psychiatry, 11, 245-254.

Rothstein, D. A. (1966). Presidential assassination syndrome II: Application to Lee Harvey Oswald. Archives of General Psychiatry, 15, 260-266. 
Rothstein, D. A. (1971). Presidential assassination syndrome: A psychiatric study of the threat, the deed, and the message. In W. J. Crotty (Ed.), Assassination and the political order (pp. 161-222). New York: Harper \& Row.

Sebastiani, J. A., \& Foy, J. L. (1965). Psychotic visitors to the White House. American Journal of Psychiatry, 122, 679-686.

Shore, D., \& Filson, C. R. (1985). Violent crime arrests of former White House cases. Paper presented at the annual meeting of the American Psychiatric Association, Dallas.

Shore, D., Filson, C. R., Davis, T. S., Olivos, G., DeLisi, L., \& Wyatt, R. J. (1985). White House cases: Psychiatric patients and the Secret Service. American Journal of Psychiatry, 142, 308-312.

Slomich, S. J., \& Kantor, R. E. (1969, March). Social psychopathology of political assassinations. Bulletin of the Atomic Scientists, 25, 9-12.

Socarides, C. W. (1979). Why Sirhan killed Kennedy: Psychoanalytic speculations on an assassination. Journal of Psychohistory, 6, 447-460.

Takeuchi, J., Solomon, F., \& Menninger, W. W. (1981). Behavioral science and the Secret Service. Washington, DC: National Academy Press.

Weinstein, E. A., \& Lyerly, O. G. (1969). Symbolic aspects of presidential assassination. Psychiatry, 32, 1-11.

Weiz, A. E., \& Taylor, R. L. (1969). American presidential assassinations. Diseases of the Nervous System, 30, 658-668.

Zager, L. D. (1983). The MMPI-based classification sytem: A critical review of derivation procedures and recent investigations of its generalizability and dynamic features. $F C I$ Research Reports (Vol. 12, No. 1). Tallahassee, FL: Federal Correctional Institution, 32301.

Edwin I. Megargee has been Professor of Psychology at The Florida State University since 1970; from 1980 through 1985 he served as a consultant to the United States Secret Service, Intelligence Division. Throughout his career he has maintained a continuing interest in psychological assessment and in violent behavior, both of which are reflected in the present article. 